\title{
DESEMPENHO, CARACTERISTICAS DE CARCAÇA E ORGÃOS DE COELHOS FILHOS DE MATRIZES ORIUNDAS DE DOIS CRUZAMENTOS
}

\author{
DENARDIN, lone Terezinha ${ }^{1}$; \\ BRUM JÚNIOR, Berilo de Souza ${ }^{2}$; \\ DIONELLO, Nelson José Laurino ${ }^{3}$; \\ SEVERO, Marcelo Machado ${ }^{4}$; \\ NIGELISKII, André Fogaça ${ }^{4}$; \\ LICINIO, Aline Stangarlin ${ }^{5}$; \\ SANTOS, Douglas Rubenich dos ${ }^{6}$.
}

Recebido: 05/03/15

Aceito: 31/10/15

\footnotetext{
${ }^{1}$ Doutoranda do PPGZ/UFPEL; ${ }^{2}$ Prof. Co-orientador - Colégio Politécnico (UFSM); ${ }^{3}$ Prof. Orientador (UFPEL);

${ }^{4}$ Aluno do curso de Graduação em Zootecnia (UFSM); ${ }^{5}$ Aluno do curso Técnico em Agroindústria (UFSM); ${ }^{6}$ Aluno do curso de Graduação em Medicina Veterinária (UFSM).
}

\section{RESUMO}

C

om o objetivo de avaliar o desempenho de coelhos oriundos de dois grupos genéticos, foram utilizados 456 coelhos filhos de matrizes cruzadas de Nova Zelândia branco (NZb) com Chinchila (CH) e de NZb com Califórnia (CF). Todas as matrizes foram acasaladas com machos híbridos (Gigante de Flândres $x$ Prateado de Champagne). As matrizes foram alojadas em gaiolas de arame galvanizado com comedouro semi-automático metálico, bebedouro tipo nipple e ninho acoplado de madeira com $60 \times 30 \times 30 \mathrm{~cm}$. Os láparos foram pesados diariamente do nascimento até os 30 dias de idade. Quando cada lote atingiu idade média de 35 dias, os animais foram desmamados e avaliados quanto ao desempenho pós-desmame. Nessa fase os animais foram alojados, em dupla, em gaiolas de arame galvanizado contendo comedouro tipo pote de barro, bebedouro automático tipo nipple e prancha de descanso. A pesagem dos coelhos, bem como a pesagem da ração e das sobras foi realizada a cada 14 dias e a avaliação do desempenho dos animais e cálculo da conversão alimentar foi feita até os 90 dias de idade. Não ocorreram diferenças entre os grupos genéticos para número de láparos por ninhada até o desmame, no peso corporal, no ganho de peso, no consumo de ração, na conversão alimentar até 90 dias de idade, no peso pré-abate, peso absoluto e relativo de patas e pele, de coração e de vísceras. Porém, os animais oriundos de Chinchila apresentaram maior peso absoluto e relativo de fígado, enquanto animais oriundos de Califórnia apresentaram maior rendimento de carcaça e peso absoluto e relativo de cabeça. Observou-se em ambos os grupos genéticos uma redução linear no número de láparos por ninhada até os 30 dias de idade devido à mortalidade prédesmame. $O$ peso médio dos láparos apresentou efeito quadrático crescente, com maior crescimento depois dos 21 dias, efeito esse causado provavelmente por ser a fase em que os filhotes deixam o ninho e iniciam a ingestão de ração peletizada além do leite materno. $O$ 
peso corporal, o ganho de peso e o consumo de ração aumentaram linearmente em ambos os tratamentos, com o avanço da idade, além de ocorrer piora na conversão alimentar. Conclui-se que os dois cruzamentos são viáveis, porém animais com $25 \%$ de Califórnia apresentaram melhor rendimento de carcaça do que animais com $25 \%$ de Chinchila, quando usados em mestiçagem.

Palavras-chave: Califórnia. Cunicultura. Chinchila. Cruzamento. Nova Zelândia branca.

\section{INTRODUÇÃO}

Em 2011 o Brasil contava com uma população de 233.607 coelhos. O maior efetivo desta espécie encontra-se nos estados do Rio Grande do Sul (40,3\%), do Paraná (17,9\%) e de Santa Catarina $(16,7 \%)$, totalizando $74,9 \%$ de todo o efetivo nacional (IBGE, 2011).

Dentre as alternativas de produção de proteína animal, o coelho pode ser considerado uma opção para abastecer desde grandes centros urbanos como para complementar a alimentação dos habitantes das pequenas propriedades rurais e até mesmo de áreas suburbanas (MOURA, 2011).

Segundo Cheeke (1989) e Finzi (2000), esses animais possuem como principal característica a alta capacidade reprodutiva, curto intervalo de gerações e rápido crescimento, além de pequeno tamanho corporal, necessitando de reduzido espaço físico para a sua criação, características indicativas da aptidão da espécie para a produção de carne sob diversas condições.

A carne de coelho ainda é pouco difundida devido a problemas como a falta de tradição na produção e consumo, pois muitos o consideram apenas um animal de estimação, e pela falta de incentivos governamentais à pesquisa e a ausência de abatedouros especializados oficiais (FERREIRA et al. 2010).

Uma alternativa para a ampliação da produção de carne de coelhos no Brasil como commodity agrícola é o desenvolvimento da cunicultura em pequena escala, em propriedades de agricultura familiar, para melhorar a qualidade de vida nessas áreas rurais ou suburbanas, em sistema integrado com outras atividades, visando o aproveitamento dos subprodutos de culturas e a produção orgânica (LUKEFAHR et al., 2004). Além disso, há a 
possibilidade do uso dos dejetos como adubo orgânico através do processo de compostagem e vermicompostagem (BRUM JR, 2012).

A crescente busca por alimentos saudáveis, a necessidade de atender consumidores cada vez mais exigentes e a competitividade pelo mercado de carne faz com que os produtores se especializem constantemente nas suas produções. O uso de linhagens de dupla aptidão foi substituído por linhagens especializadas para uma finalidade (carne, pele ou pêlo) e os subprodutos comercializados como a pele, vísceras e dejetos, no caso da produção de carne, fornecem um complemento de renda ao produtor.

Com a finalidade de alcançar melhores resultados, muitos criadores adotam a utilização de animais cruzados no plantel. O cruzamento garante aumento na heterose, que é caracterizada como a superioridade dos filhos em relação à média dos pais e com isso assegura a impressão das características positivas de duas ou mais raças nos descendentes, sejam eles reprodutrizes ou animais destinados ao abate, de acordo com o objetivo. Os coelhos podem ser criados para carne, pele ou para animais de estimação (Pet). Porém Samkol e Lukefahr (2008) citam que, além disso, produzem subprodutos como o couro para a indústria de artefatos ou para a produção de gelatina, os pêlos para fabricação de feltro, o cérebro para a extração de tromboplastina, as vísceras para rações animais e o esterco para adubação orgânica. Além disso, segundo Couto (2006), constitui-se numa das quatro espécies animais mais utilizadas em laboratório, juntamente com ratos, camundongos e cobaias, tendo propiciado avanços significativos na pesquisa biomédica.

Dessas três classes (carne, pele e pet) existem diversas raças especializadas de acordo com a sua aptidão. Animais de porte médio e grande são os mais indicados para a produção de carne e entre essas raças destacam-se a Nova Zelândia branco (NZb), a Califórnia (CA) e a Chinchila $(\mathrm{CH})$. Embora a eficiência da produção de coelhos esteja atrelada a fatores genéticos, de manejo, nutricionais e sanitários, e seja difícil quantificar a importância isolada de cada um deles, sabe-se que o componente genético é um fator de extrema importância no momento de se implantar um sistema produtivo de criação de coelhos, pois a aplicação correta de todos os demais fatores em animais de baixo potencial genético não reflete em melhorias nos índices produtivos. 
A seleção de indivíduos com base em características produtivas e reprodutivas é considerada relativamente difícil, em razão da complexidade de sua base genética e do elevado grau de influência do ambiente a que estão sujeitos, podendo gerar interação genótipo x ambiente (SAKAGUTI, 1994), principalmente nas características de baixa herdabilidade.

Para garantir esses resultados é necessário o trabalho constante de melhoramento genético, em que deve haver rigidez principalmente na seleção de machos, os quais devem passar por uma criteriosa seleção, uma vez que os reprodutores têm maior importância na contribuição da geração seguinte do que as fêmeas, devido ao seu uso em várias matrizes, podendo ser aumentada com a utilização de inseminação artificial (DO CARMO et al., 2011).

Nesse sentido, Moura (2011) avaliando raças puras e mistas, não encontrou diferença no desempenho pré-desmame de filhos de matrizes Botucatu e mestiças. Por outro lado, Chiericato et al. (1993) trabalhando com animais Nova Zelândia branco e duas linhagens híbridas encontraram diferença no peso aos 43 dias e aos 85 dias de idade, quando foram abatidos. Estudos sobre o cruzamento das raças Chinchila e Nova Zelândia branco serviram para definir que a raça Nova Zelândia branco, de origem americana, é boa produtora de carne, sendo considerada a raça mais adequada para este fim, uma vez que os láparos podem atingir 1,8 a $2 \mathrm{~kg}$ com idade de 8 a 10 semanas e de 3,5 a $5 \mathrm{~kg}$ de peso corporal quando fisiologicamente adultos (MOURA, 2011).

Por sua vez, a raça Chinchila, de origem alemã, apresenta porte médio, alcançando um peso médio de 3 a 4,5 kg. É uma raça rústica, bastante precoce e prolífera, possuindo capacidade de gestar de 6 a 10 láparos por parto (MOURA, 2011).

Já a raça Califórnia, originária dos Estados Unidos da América (EUA) e caracterizada por animais brancos com extremidades pretas, é de porte médio e bastante utilizada em programas de cruzamentos, principalmente a linha materna (MELLO; SILVA, 2003).

Devido à necessidade de promover um melhor aproveitamento da cunicultura no Brasil, o objetivo desse trabalho foi avaliar as características de desempenho, de carcaça e órgãos de coelhos oriundos de duas linhagens de matrizes híbridas. 


\section{MATERIAL E MÉTODOS}

O experimento foi realizado no Laboratório Experimental de Cunicultura do Instituto Federal Farroupilha (LECIFF) e no Setor de Cunicultura do Colégio Politécnico da Universidade Federal de Santa Maria (UFSM) no período de junho de 2012 até dezembro de 2013, sendo desenvolvido em duas etapas. A primeira (do nascimento até o desmame) foi realizada no LECIFF campus Júlio de Castilhos - RS.

Foram utilizados 456 coelhos oriundos de dois grupos genéticos, fêmeas $\mathrm{CH}$ (Chinchila $\mathrm{x}$ Nova Zelândia branco), CF (Califórnia x Nova Zelândia branco) acasaladas com machos Prateado de Champagne x Gigante de Flândres. A variação ocorria no avô materno, em que no primeiro grupo $(\mathrm{CH})$ foram utilizados animais da raça Chinchila e no segundo grupo (CF) foram utilizados animais da raça Califórnia, resultando em $25 \%$ de cada raça nos animais avaliados.

O experimento iniciou com 20 matrizes $\mathrm{CH}$ e 20 matrizes $\mathrm{CF}$, todas acasaladas aos 5 meses de idade e re-acasaladas a cada desmame, com intervalo médio entre partos de 65 dias (30 dias de gestação e mais 35 dias de lactação), com cada fêmea totalizando seis partos durante o período.

O galpão do LECIFF possuía $16 \mathrm{~m}$ de comprimento $\times 7 \mathrm{~m}$ de largura, com pé direito de $4 \mathrm{~m}$. As matrizes foram alojadas individualmente em gaiolas de arame galvanizado com comedouro externo metálico semiautomático, sendo alimentadas à vontade com ração comercial. As gaiolas também possuíam bebedouro automático tipo nipple e ninho de madeira acoplado de $60 \times 30 \mathrm{~cm}$, que era aberto para acesso das fêmeas somente dois dias antes da data prevista para o parto. Depois do parto os láparos foram contados e pesados diariamente até os 30 dias de idade para a avaliação do peso corporal diário e, com isso, a avaliação do crescimento dos animais, quando então se iniciou a segunda etapa do trabalho, com todos os animais com mesma idade.

A segunda etapa foi desenvolvida no Setor de Cunicultura do Colégio Politécnico da UFSM, no período de agosto de 2012 a dezembro de 2013. 
O galpão apresentava $30 \mathrm{~m}$ de comprimento $\times 7 \mathrm{~m}$ de largura e $3 \mathrm{~m}$ de pé direito, posicionado no sentido leste-oeste, com laterais teladas para permitir a ventilação e evitar entrada de predadores e cortinas móveis para auxiliar no controle da temperatura. $O$ galpão possuía três linhas de gaiolas de arame galvanizado, com 26 gaiolas de $60 \times 60 \times 40 \mathrm{~cm}$ por linha, equipadas com bebedouro tipo nipple, comedouro tipo pote de barro e prancha de repouso para os animais.

Foram utilizados 456 coelhos desmamados aos 35 dias de idade, oriundos dos cruzamentos da primeira etapa, conforme recomendação de Mello e Silva (2003), tatuados e alojados em dupla, sendo que permaneceram até 90 dias de idade recebendo ração peletizada para coelhos com $17 \%$ de proteína bruta e $14 \%$ de fibra bruta durante todo o período experimental.

As pesagens foram realizadas aos 35, 49, 63, 77 e 90 dias para a avaliação do ganho de peso. Também foi realizada a pesagem da quantidade de ração fornecida e as sobras, para a avaliação do consumo e da conversão alimentar. A água e a ração foram fornecidas à vontade. A ração suja de urina e/ou fezes nos comedouros era pesada e substituída por ração nova e as pranchas de repouso eram limpas sempre que apresentavam qualquer sujidade, bem como as gaiolas.

Aos 90 dias de idade os animais foram pesados para a obtenção do peso pré-jejum. Depois de $12 \mathrm{~h}$ em jejum os animais foram pesados novamente para a obtenção do peso após o jejum e então foram imediatamente abatidos. O abate foi realizado através de insensibilização por concussão cranial seguida de sangria, esfola e evisceração. Foi avaliado o peso da cabeça, da pele com as patas, das vísceras, do coração, do fígado e da carcaça quente, para posterior avaliação do peso relativo dos mesmos, conforme registrado no CEEA da UFPEL, número 7119.

O delineamento experimental foi o inteiramente casualizado (DIC), sendo avaliado o efeito do genótipo de animais oriundos de cruzamento. Os dados foram submetidos à análise de variância e teste $\mathrm{F}$ a $5 \%$ de significância. O efeito da idade sobre o desempenho foi avaliado através de regressão. Utilizou-se o programa estatístico SAS (1996). 


\section{RESULTADOS E DISCUSSÃO}

O desempenho dos láparos do nascimento aos 30 dias de idade, medido através do peso corporal médio, não apresentou diferença entre os grupos genéticos avaliados (Figura 1). Estes resultados corroboram com Moura (2011) que não encontrou diferença ao avaliar o desempenho pré-desmame de filhos de matrizes Botucatu e mestiças. Por outro lado, Chiericato et al. (1993) trabalhando com animais Nova Zelândia branco e duas linhagens híbridas encontraram diferença no peso aos 43 dias e aos 85 dias, quando foram abatidos.

Para os dois grupos genéticos, o peso corporal médio dos láparos apresentou um efeito quadrático crescente do nascimento até os 30 dias de idade, conforme a Figura 1, sendo mais acentuado depois dos 21 dias de idade, quando os filhotes já deixam o ninho em busca de alimento sólido. Segundo Mello e Silva (2003), a produção de leite da coelha diminui a partir dos 21 dias de lactação, porém essa redução na produção é compensada pela ingestão de ração, que assegura o bom crescimento da ninhada. Entretanto, o número de láparos por ninhada reduziu com o avanço da idade devido à mortalidade pré-desmame, apresentando um efeito quadrático decrescente (Figura 2). O número médio de nascidos vivos por ninhada em ambos os grupos foi de 9,2 láparos, superior aos 8,53 encontrados por Moura (2011) ao utilizar coelhas primíparas mestiças da linhagem Botucatu. 


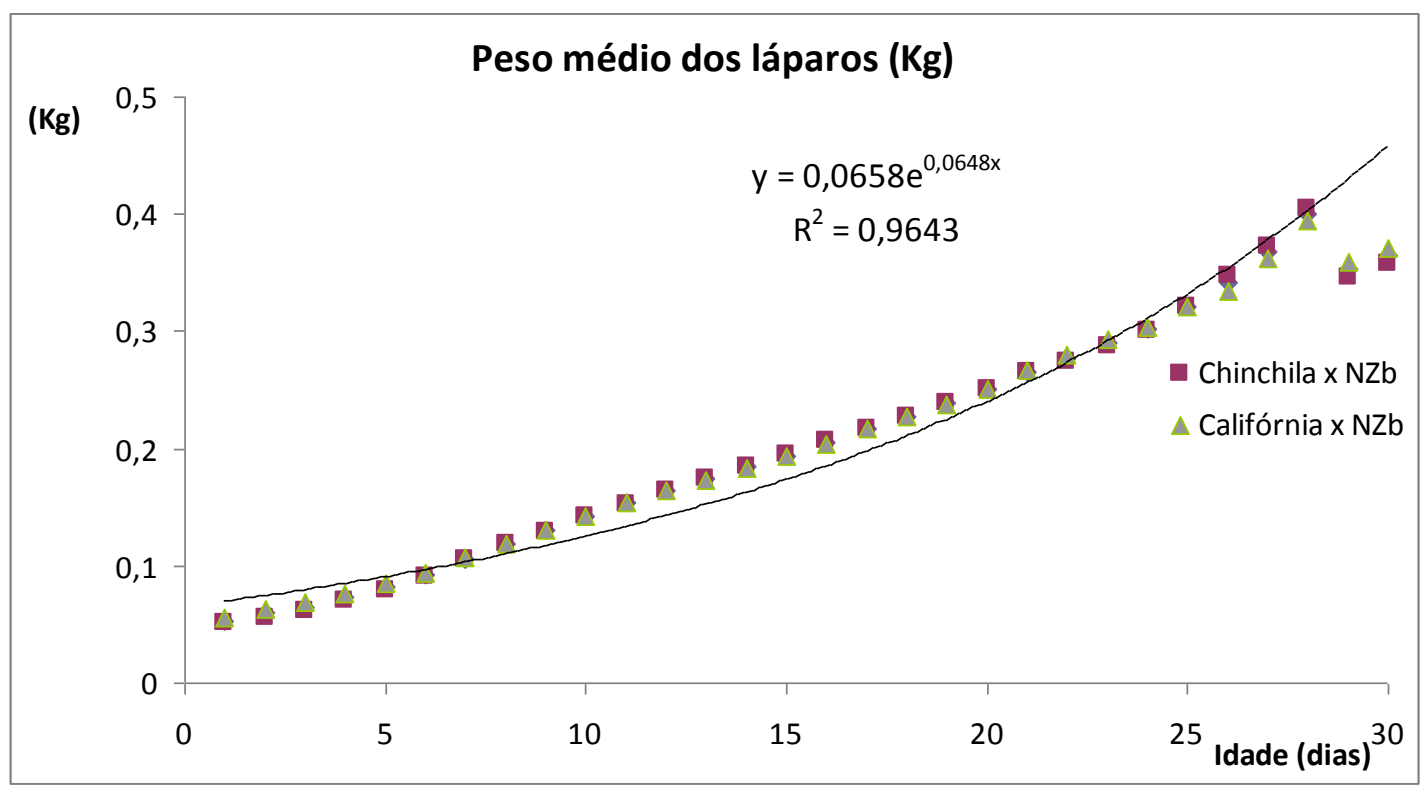

Figura 1 - Peso médio dos láparos filhos de matrizes cruzadas de Nova Zelândia branco com Chinchila ou Califórnia de 01 a 30 dias de idade.

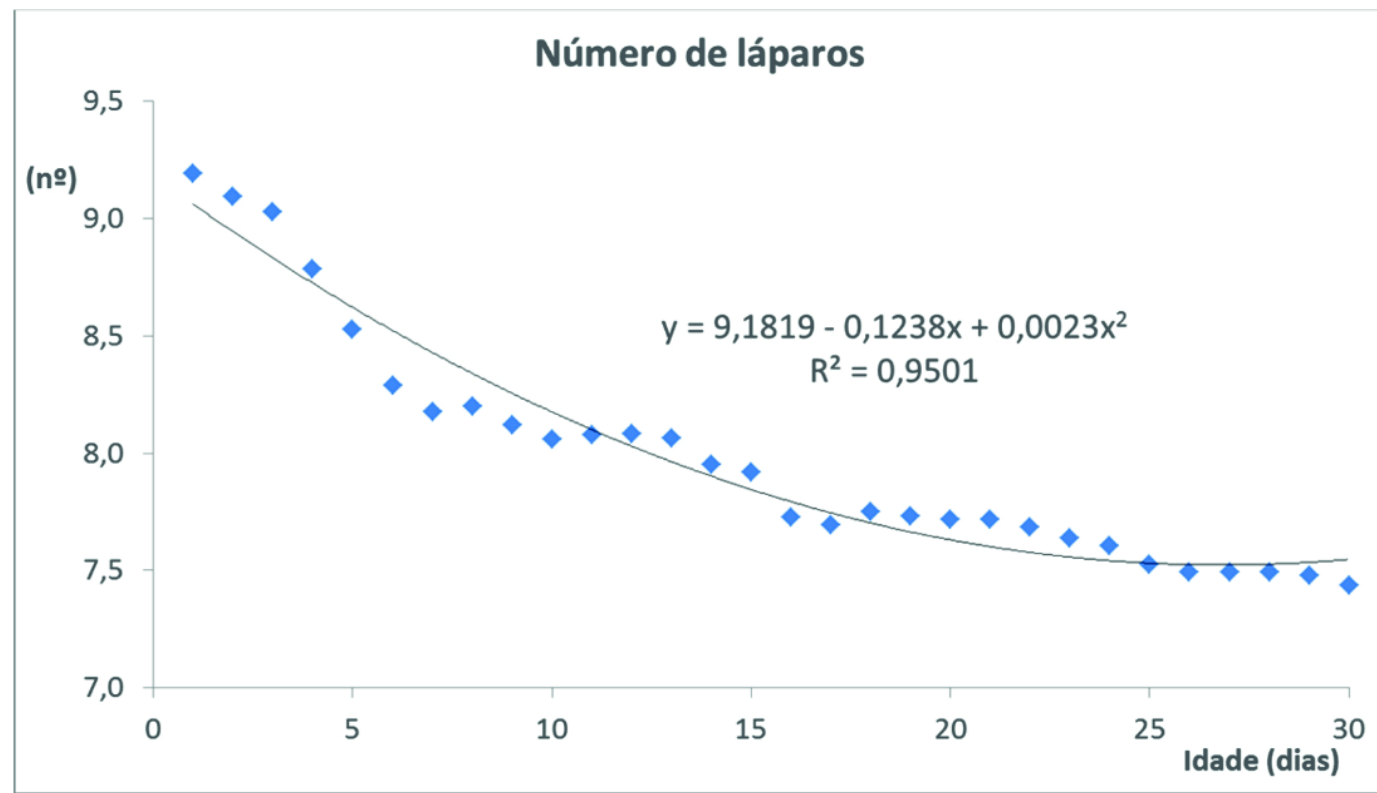

Figura 2 - Número médio dos láparos filhos de matrizes cruzadas de Nova Zelândia branco com Chinchila ou Califórnia de 01 a 30 dias de idade. 
O peso corporal, o ganho de peso, o consumo de ração e a conversão alimentar nos períodos de 35 a 49, 63, 77 e 90 dias de idade não diferiram entre os grupos genéticos avaliados conforme apresentado na Tabela 1.

Tabela 1 - Peso corporal, ganho de peso, consumo de ração e conversão alimentar de coelhos oriundos de mães CH (Chinchila x Nova Zelândia branco), CF (Califórnia x Nova Zelândia branco).

\begin{tabular}{|c|c|c|c|c|}
\hline \multirow[b]{2}{*}{ Período (dias) } & Chinchila & Califórnia & CV(\%) & $p$ \\
\hline & \multicolumn{4}{|c|}{ Peso corporal (kg) } \\
\hline 35 & 0,67 & 0,65 & 24,41 & 0,20 \\
\hline 49 & 1,11 & 1,10 & 22,31 & 0,69 \\
\hline 63 & 1,63 & 1,63 & 18,25 & 0,96 \\
\hline 77 & 2,14 & 2,14 & 16,18 & 0,99 \\
\hline 90 & 2,51 & 2,53 & 14,43 & 0,51 \\
\hline Período (dias) & \multicolumn{4}{|c|}{ Ganho de peso (kg) } \\
\hline $35-49$ & 0,44 & 0,46 & 38,27 & 0,18 \\
\hline $35-63$ & 0,95 & 0,98 & 23,47 & 0,20 \\
\hline $35-77$ & 1,45 & 1,49 & 18,56 & 0,30 \\
\hline $35-90$ & 1,82 & 1,88 & 16,63 & 0,09 \\
\hline Período (dias) & \multicolumn{4}{|c|}{ Consumo de ração (kg) } \\
\hline $35-49$ & 1,08 & 1,16 & 28,04 & 0,07 \\
\hline $35-63$ & 2,62 & 2,82 & 22,64 & 0,20 \\
\hline $35-77$ & 4,42 & 4,64 & 21,11 & 0,09 \\
\hline $35-90$ & 5,90 & 6,36 & 21,90 & 0,10 \\
\hline Período (dias) & \multicolumn{4}{|c|}{ Conversão alimentar } \\
\hline $35-49$ & 2,46 & 2,51 & 29,27 & 0,87 \\
\hline $35-63$ & 2,76 & 2,87 & 18,76 & 0,47 \\
\hline $35-77$ & 3,04 & 3,12 & 18,33 & 0,61 \\
\hline $35-90$ & 3,24 & 3,38 & 19,73 & 0,97 \\
\hline
\end{tabular}


Esses resultados concordam com os obtidos por Mello e Silva (2003) que ao utilizarem animais das raças Califórnia e Chinchila obtiveram resultados de desempenho semelhante. Por sua vez, AL-Dobaib (2010) avaliando animais de quatro linhagens: V-line, Saudi-1, Saudi2 e Saudi-3 não encontrou diferenças no desempenho, exceto para o ganho de peso da linhagem Saudi-2, que foi superior as demais. Ao comparar três linhagens de coelhos tipo carne, Pla et al. (1998) encontraram diferença no peso corporal ao abate (90 dias). Já Zeferino et al. (2011) compararam coelhos da linhagem Botucatu com animais cruzados (Botucatu x NZb) e encontraram maior peso corporal e ganho de peso ao abate em condições de alta temperatura, porém em condições de temperaturas mais amenas, não observaram diferenças nos dados produtivos entre as linhagens.

Estes resultados também concordam com Ozimba e Lukefahr (1991) que não encontraram variação no desempenho de várias linhagens cruzadas, porém verificaram superioridade no peso vivo e peso de carcaça quando comparados aos animais puros da raça NZb.

No entanto, no presente estudo houve diferenças entre as idades avaliadas para os dois grupos genéticos, uma vez que o peso corporal, o ganho de peso e o consumo de ração aumentaram linearmente com o avanço da idade, enquanto a conversão alimentar apresentou piora linear, conforme Figura 3. 


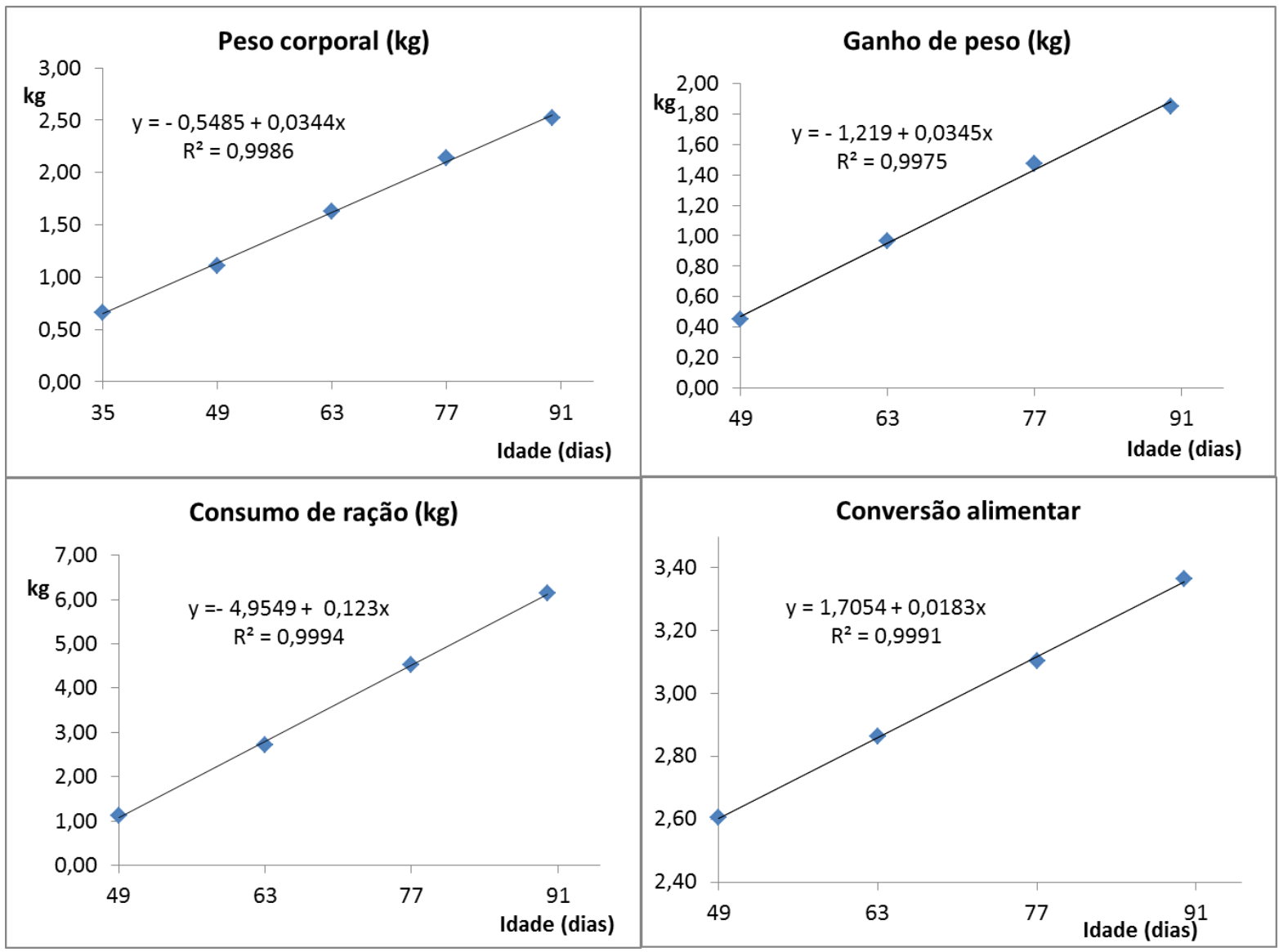

Figura 3 - Média de peso corporal, ganho de peso, consumo de ração e conversão alimentar de coelhos filhos de matrizes CH (Chinchila x Nova Zelândia branco), CF (Califórnia x Nova Zelândia branco) dos 35 aos 90 dias.

O crescimento dos animais corrobora com o obtido por Mello e Silva (2003), que observaram um peso corporal entre 1,8 e $2,3 \mathrm{~kg}$, aos 70 dias de idade.

Os pesos pré-jejum, pós-jejum, de peles com patas, de vísceras e de coração não foram afetados pelos genótipos avaliados, bem como os pesos relativos dos mesmos. O peso absoluto e relativo de fígado foi maior nos animas oriundos de cruzamento com Chinchila $(P<0,01)$. Diferentemente, Nofal et al. (1995) encontraram maior peso relativo de fígado e maior rendimento de carcaça em animais da raça Califórnia quando comparados com animais cruzados com Nova Zelândia branco. No presente experimento, o peso absoluto e relativo de cabeça, bem como os rendimentos de carcaça antes e depois do jejum foram superiores nos animais resultantes do cruzamento com Califórnia $(P<0,05)$, certamente por 
apresentarem maior peso corporal e, consequentemente, maior peso da cabeça, conforme a

Tabela 2.

Tabela 2 - Peso absoluto e peso relativo pré-jejum, pós-jejum, de cabeça, de peles com patas, de coração, de vísceras e de fígado de coelhos oriundos de mães cruzadas de Nova Zelândia branco com Chinchila ou Califórnia.

\begin{tabular}{l|cc|c|c}
\hline & Chinchila & Califórnia & CV(\%) & p \\
\hline \multicolumn{4}{|c}{ Peso absoluto (Kg) } \\
\hline Pré-jejum & 2,51 & 2,53 & 14,22 & 0,60 \\
Pós-jejum & 2,42 & 2,44 & 13,77 & 0,45 \\
Cabeça & 0,20 & 0,21 & 12,69 & 0,01 \\
Patas e peles & 0,36 & 0,36 & 17,35 & 0,35 \\
Coração & 0,01 & 0,01 & 35,76 & 0,72 \\
Vísceras & 0,37 & 0,38 & 15,59 & 0,35 \\
Fígado & 0,06 & 0,05 & 23,41 & 0,00 \\
Carcaça & 1,32 & 1,35 & 14,97 & 0,12 \\
\hline & & \multicolumn{4}{c}{ Peso relativo (\%) } & \\
\hline Pós-jejum & 96,31 & 96,66 & 6,11 & 0,55 \\
Cabeça & 7,90 & 8,15 & 10,42 & 0,00 \\
Patas e peles & 14,16 & 14,17 & 10,44 & 0,95 \\
Coração & 0,36 & 0,35 & 33,87 & 0,63 \\
Vísceras & 14,85 & 15,04 & 13,71 & 0,36 \\
Fígado & 2,44 & 2,27 & 19,92 & 0,00 \\
Carcaça & 54,66 & 55,42 & 6,34 & 0,03 \\
\hline
\end{tabular}

Esses resultados concordam com os obtidos por AL-Dobaib (2010), que avaliou características de carcaça de quatro linhagens de coelhos tipo carne. De modo semelhante, Pla et al. (1998) encontraram diferença no peso de carcaça ao comparar três linhagens de coelhos tipo carne. Já Lukefar e Ozimba (1991) não encontraram diferenças nas características pós-abate entre coelhos das raças Califórnia, NZ branco e cruzados. 


\section{CONCLUSÃO}

Os dois cruzamentos apresentaram características adequadas para produção de carne, porém, animais com $25 \%$ da raça Califórnia têm melhor rendimento de carcaça do que animais com $25 \%$ da raça Chinchila, quando usados em mestiçagem.

\section{PERFORMANCE, CARCASS AND ORGANS CHARACTERISTICS OF OFFSPRING RABBITS FROM MOTHERS ARISING FROM TWO CROSSINGS}

\section{ABSTRACT}

I

$n$ order to evaluate the performance of rabbits from two genetic groups 456 offspring rabbits from cross arrays of New Zealand white (NZB) with Chinchilla (CH) and from NZB with California (CF) were used. All matrixes were mated with hybrid males (Giant Flanders $x$ Champagne Silver). The matrixes were housed in galvanized wire cages with metallic semi-automatic feeder, nipple drinker and coupled wooden nest with $60 \times 30 \times 30$ $\mathrm{cm}$. The young rabbits were weighed daily from birth until 30 days old. When each lot reached an average age of 35 days, the animals were weaned and assessed for post-weaning performance. In this phase the animals were housed in pairs, in galvanized wire cages containing clay pot-type feeder, nipple-type automatic water dispenser and a resting board. The weighing of rabbits as well as their food and remaining were performed every 14 days and the animal performance evaluation and calculation of feed conversion were made up until 90 days of age. There were no differences between genetic groups in the number of young rabbits per litter until weaning, body weight, weight gain, feed intake, feed conversion until 90 days of age, pre-slaughter weight, absolute and relative weight of paws and skin, heart and viscera. However, the animals from Chinchilla presented greater absolute and relative liver weight, while animals from California showed higher carcass income and greater absolute and relative weight of head. It was observed in both genetic groups a linear reduction in the number of young rabbits per litter until 30 days of age because of pre-weaning mortality. The average weight of young rabbits presented quadratic increase with greater growth after 21 days, this effect was probably caused because this is the stage when the rabbits leave the nest and begin the pelleted feed intake in addition to breast milk. Body weight, weight gain and feed intake increased linearly in both treatments with age advance, besides the worsening of feed conversion. It was concluded that the two crossings are feasible, but animals with $25 \%$ of California showed better carcass income than animals with $25 \%$ of Chinchilla, when they are used in crossbreeding.

Keywords: California. Rabbits. Chinchilla. Crossing. White New Zealand. 


\section{DESEMPEÑO, CARACTERÍSTICAS DE ESQUELETO Y ORGANOS DE CONEJOS HIJOS DE MATRICES ORIUNDAS DE DOS CRUZAMIENTOS}

\section{RESUMEN}

$E^{\prime}$ experimento fue realizado en el Laboratorio Experimental de Cunicultura del Instituto Federal Farroupilha (LECIFF), y en el Sector de Cunicultura del Colegio Politécnico de la UFSM en el periodo de junio de 2012 hasta diciembre de 2013, con el objetivo de evaluar el desempeño de conejos oriundos de dos grupos genéticos. Fueron utilizadas 456 conejos hijos de matrices cruzadas de Nueva Zelandia blancas (NZb) con chinchilla (CH) y de NZb con California (CF). Todas las matrices fueron apareados con machos híbridos (Gigante de Flandes $x$ Plateado de Champagne). Las matrices fueron alojadas en jaulas de alambre galvanizado con comedero semiautomático metálico, bebedero tipo nipple y nido acoplado de madera con $60 \times 30 \times 30 \mathrm{~cm}$. Los gazapos fueron pesados diariamente del nacimiento hasta los 30 días de edad. Cuando cada lote tuvo edad media de 35 días, los animales fueron desmamados y conducidos hasta el sector de cunicultura del Colegio Politécnico para la evaluación del desempeño pos desmame. En esta fase los animales fueron alojados en pares, en jaulas de alambre galvanizado contiendo comedero tipo pote de barro, bebedero automático tipo nipple y tablón de descanso. El pesaje de los conejos, bien como el pesaje de la ración y de las sobras fue realizada a cada 14 días para evaluar el desempeño de los animales y hacer el cálculo de la conversión alimentar hasta los 90 días de edad. No hubieron diferencias entre los grupos genéticos para números de gazapos por camada hasta el desmame, en el peso corporal, en la ganancia de peso, en el consumo de ración, en la conversión alimentar hasta 90 días de edad, en el peso pre abate, peso absoluto y relativo de patas y piel, de corazón y de vísceras. Pero, los animales oriundos de chinchilla presentaron mayor peso absoluto y relativo de hígado, en cuanto animales oriundos de California presentaron mayor rendimiento de carcaza y peso absoluto y relativo de cabeza. Fue observado una reducción linear en el número de gazapos por camada hasta los 30 días de edad debido a la mortalidad pre desmame. El peso medio de los gazapos presentó efecto cuadrático creciente, con mayor crecimiento después de los 21 días, efecto ese causado probablemente por ser la fase en que los cachorros dejan el nido e inician la ingestión de ración peletizada, además de la leche materna. El peso corporal, la ganancia de peso y el consumo de ración aumentaron linealmente con el avance de la edad, además de ocurrir empeoramiento de la conversión alimentar. Se concluye que los dos cruzamientos son viables, pero animales con $25 \%$ de California presentaron mejor rendimiento de carcaza que animales con $25 \%$ de chinchilla, cuando usados en cruzamientos.

Palabras clave: California. Conejos. Chinchillas. Cruzamientos. Nueva Zelanda blanco. 


\section{REFERÊNCIAS}

AL-DOBAIB, S. N. Effect of diets on growth, digestibility, carcass and meat quality characteristics of four rabbit breeds. Saudi Journal of Biological Sciences, v. 17, n. 1, p. 8393, 2010.

BRUM JR, B. S. A cunicultura como alternativa ao combate à fome. In: SEMINÁRIO NACIONAL DE CIÊNCIA E TECNOLOGIA EM CUNICULTURA. 4, Palestra. Botucatu-SP, 2012.

CHEEKE, P. R. Produção e alimentação de coelhos em sistema de produção agrícola tropical e subtropical. Informe agropecuário, Belo Horinzonte, v. 14, n. 159, p. 9-13, 1989.

CHIERICATO, G. M.; RIZZI, C.; ROSTELLATO, V. Effect of genotype and environmental temperature on the performance of the Young meat rabbit. World Rabbit Science, Valencua, v. 1, n. 3, p. 119-125, 1993.

COUTO, S. E. R. Criação e manejo de coelhos. In: ANDRADE, A.; PINTO, S. C.; OLIVEIRA, R. S. Animais de laboratório: Criação e Experimentação. Rio de janeiro: Fiocruz, 2006. p. 93-113.

DO CARMO, F.; NICOLI, G. M.; OLIVEIRA, L. D. Melhoramento Genético x Biodiversidade. 2011. Disponível em: http://www.artigonow.com.br/ciencias/biologia/melhoramentogenetico-x-biodiversidade. Acesso em: 05 abril 2014.

FERREIRA, W. M. et al. The rabbit Production in Brazil In: RABBIT CONGRESS OF THE AMERICAS, 4, 2010, Córdoba. Proceedings. Córdoba: American Branch of the World Rabbit Science Association, 2010. p. 1-8.

FINZI, A. Raising rabbits for food security. In: WORLD RABBIT CONGRESS, 7, 2010, Valencia. Proceedings, Valencia: World Rabbit Science Association, 2000. p. 13-38.

IBGE. INSTITUTO BRASILEIRO DE GEOGRAFIA E ESTATÍ́STICA. Senso Agropecuário. Produção de Pecuária Municipal, v. 39, p. 1-63. 2011. Disponível em: http://www.ibge.gov.br. Acesso em: 15 set. 2014.

LUKEFAHR, S. D.; OZIMBA, C. E. Prediction of carcass merit from live body measurements in rabbits of four breed-type. Livestock Production Science, v. 29, p. 323-334. 1991.

LUKEFAHR, S. D.; CHEEKE, P. R.; MCNITT, J. I.; et al. Limitations of intensive meat rabbit production in North America: a review. Canadian Journal of Animal Science, Ottawa, v. 84, p. 349-360, 2004.

MELLO, H. V.; SILVA, J. F. Criação de Coelhos. Viçosa: Aprenda Fácil, 2003. 259p. 
MOURA, A. S. A. M. T. Fatores genéticos e de ambiente na produção de coelhos Botucatu. Botucatu: UNESP, 2011. Tese (Livre-Docente) - Faculdade de Medicina Veterinária e Zootecnia, Universidade Estadual Paulista Júlio de Mesquita Filho, 2011.

NOFAL, R. Y.; TOTH, S.; VIRAG, G. Y. Carcass traits of purebred and crossbred rabbits. World Rabbit Science, v. 3, n. 4, p. 167-170, 1995.

OZIMBA, C. E.; LUKEFAHR, S. D. Evaluation of purebred and crossbred rabbits for carcass merit. Journal of Animal Science, Champaign, v. 69, p. 2371-2378, 1991.

PLA, M.; GUERRERO, L.; GUARDIA, D.; et al. Carcass characteristics and meat quality of rabbit lines selected for different objectives: I. Between lines comparison. Livestock Production Science, v. 54, p. 115-123, 1998.

SAKAGUTI, E. S. Utilização de técnicas de análise multivariada na avaliação de cruzamentos dialélicos em coelhos. Viçosa: UFV, 1994, 184p. Dissertação (Mestrado em Zootecnia), Faculdade de Zootecnia, Universidade Federal de Viçosa, 1994.

SAS. Statistical Analysis System Institute. SAS/STAT. User's guide, version $6.11 .4^{\text {th }}$ ed. Cary, v. 2, 1996. 842p.

SAMKOL, P.; LUKEFAHR, S. D. A challenging role for organic rabbit production towards poverty alleviation in South East Asia. In: WORLD RABBIT CONGRESS, 9, 2008, Verona. Proceedings. Verona: Fondazione Iniziative Zooprofilattiche e Zootecniche-Brescia-Italy, june, 13, 2008. p. 419-445.

ZEFERINO, C. P.; MOURA, A. S. A. M. T.; FERNANDES, S.; KANAYAMA, J. S.; SCAPINELLO, C.; SARTORI, S. R. I. Genetic group $x$ ambient temperature interaction effects on physiological responses and growth performance of rabbits. Livestock Science, v. 140, n. 1-3, p. 177-183, 2011.

Autor para correspondência: lone Terezinha Denardin. Av. Roraima no 1000, Cidade Universitária - prédio 70, Bairro Camobi, Santa Maria - RS. CEP: 97105-900. ionedenardin@gmail.com 